\title{
Indo-Mongolian Relations in Present Era
}

Dr. Mukesh H. Khatik and Ms. Upasana Bhandari ${ }^{1}$

\begin{abstract}
At present, there is a good a synergy between Mongolia and India .both country has emerged as a good neighbouring country past to present and they respect each other as part of their foreign policy. Mongolia focuses today on a number of pressing domestic socio-economic issues. Unemployment, poverty, rapid urbanization and the ensuing social displacement pose potential threats to long-term stability and economic prosperity. Moreover, it becomes a more difficult task in the absence of a meaningful regional cooperation framework. India's new role in East Asia may have far-reaching consequences to the extent of benefiting Mongolia as well so far as issue of regional cooperation is concerned. Mongolia could seek India's support and recent developments in India-Mongolia ties make it more feasible. India, as a close friend and considered by Mongolia as its spiritual neighbour, would like to see Mongolia flourish and prosper in building and strengthening democratic traditions and institutions, apart from its economic and developmental achievements. Ever since Mongolia become independent till now 2021, they have been cooperate each other in all issue of bilateral and multilateral but another thing it does not mean that Mongolia does not have relation with other countries they have because of its geo-political condition and its own national interest. Most important thing relation with India both bind up with Buddhism, historically and culturally and they continued to build relation based on.
\end{abstract}

Keywords: Cultural, Historical, Economic, Security council, Defence, Cyber Security, Military, Foreign policy, Trade, Terrorism, Civilization, Bilateral, Treaty, Defence, Democracy, Global Peace.

${ }^{1}$ Dr. Mukesh H. Khatik is Assistant Professor and Head Dept. of Political Science, USSS, Gujarat University, Ahmedabad and Ms. Upasana Bhandari is an independent researcher. 


\section{Introduction}

India and Mongolia relation is more than 2750 years old historical and culturally based and it is in a good shape India's position as a third neighbour give a defined direction to Mongolia foreign policy. Traditionally Mongolia has never been neglected in India. Currently India's relations with Mongolia are getting wider but we cannot say that India is taking interest in Mongolia because of China, it has always been India's maintain its political freedom of Mongolia as it was an earlier under the influence of the Soviet Union now it should not come completely under the influence of China. However, one most must not forget that democracy and Buddhism are the key element that bind India with Mongolia in addition to successful diplomacy being pursued by the two sides towards each other after Modi took over power in 2014 India's foreign policy has taken new direction not only towards neighbours but also towards these extended neighbourhood. As regards East Asia since 1993 India's look east policy had been working well until Modi government took a resolute stand to make India's vigorous presence in the region the result was that look east policy was change into active policy with this new policy Northeast Asia also comes into promises in India's foreign policy. Mongolia which belongs to the Northeast Asia became a key country in India active policy while India became a key third neighbour country in Mongolia's foreign policy. It is also true that China has replaced the Soviet Union in Mongolia no one country can replace China in Mongolia because has made a lot of economic promotion trade and investment in Mongolia, but Mongolian public might be impressed by their excessive economic offers. Foreign Policy: Mongolia seeks to attain its foreign policy goals in a "multi-pillared" global environment. Sovereignty, national pride, national security, territorial integrity is the cornerstones of Mongolia's foreign policy. Mongolia has diplomatic relations with 140 countries in the world. Having for long lived in an external environment, which was dominated by the geographic fact of Russian and Chinese presence on its borders, Mongolia, since the decades of 90s, after complete independence and adoption of free market economic policies has pursued an independent foreign policy. Mongolia has sought to build bridges with other global players through the doctrine of "third neighbour" which includes USA, Japan, India, ROK and EU. Due to deep and ancient Buddhist links through Tibet, India is also referred to as the "spiritual neighbour" of Mongolia. Mongolia has pursued the policy of joining hands with international initiatives and multinational fora.

Over the year India relationship with Mongolia has been widening to include strategic element such as the uranium from Mongolia. Defence Corporation has grown and the militaries of the 
two countries conduct exercise "NOMAD ELEPHANT" regularly. There is also mutual consultation on between the security council of the two countries on topic like cyber securities have been given importance Mongolia strategic position at the cross junction of Central Asia Northeast Asia east West and China Russia attract major power towards. For the United States Mongolia is an important partner in its PIVOT to Asia. India should consider Mongolia as the Green Zone economic development that absorbs high tech features and production skills in a modernization process to preserve and promotional common heritage of Indo Mongolian culture is important this should serve as the basis for nurturing and pursuing future common interest there is a regular consultation between the National Security Council of India and Mongolia on issue of mutual interest in regional multilateral affairs including on the subject of terrorism in recent years Modi visit to Mongolia the renewal of defence cooperation agreement is considered to a very important as it may give a boost to India's foreign policy of engaging with the neighbours of China in a move discreet manner. There is no doubt India and Mongolia in their history and culture have created a background for political economic and defines religion in the contemporary period. That in recent years especially after Modi visit to Mongolia the strategic partnership between the two countries has been giving a boost to enhancing their bilateral relationship which has further been strengthened with the visit of the Mongolian president Battulga that to India. This only confirms that both sides give the importance to each other in their respective foreign policy.

\section{Mythological Perspective}

India and Mongolia have interacted through the medium of Buddhism over a period 2700 years this process of cultural and spiritual interaction has enriched the two civilizations through the process of give and take. The two countries continued to build relation based on shared historical cultural legacy.

\section{Diplomatic Relations with Mongolia}

Diplomatic relation between India and Mongolia were established on 24 December 1955 .India was the first country outside the soviet block to establish diplomatic relation with Mongolia India's role in security UN member for is acknowledged by the Mongolian people, Mongolia also appreciation for India's support for its admission to non-aligned movement (NAM) as a full member in 1991. Year 2020 marked the 65th anniversary of establishment of diplomatic relations. In January 1956, we had first Mongolian Ambassador in New Delhi. Indian resident 
Mission in Ulaanbaatar was opened on 22 February 1971. Earlier, Indian Ambassador in Moscow (T.N. Kaul) was concurrently accredited. Mongolians appreciate Indian's support to its membership in United Nations in 1961 which was championed by Pt. Jawaharlal Nehru. In 1991, India supported Mongolia's membership to Non-Aligned Movement (NAM). Mongolia along with India and Bhutan co-sponsored famous Resolution for the recognition of Bangladesh as an independent country in 1972

\section{Treaty of Friendly Relation: Joint declaration of 1973 \& Cooperation of 1994}

According these treaty- both country developing equally and mutually beneficial co-operation in various spheres including political, economic, trade, science, technology, health, agriculture, ecology, culture, education, communication and terrorism.

Development of links between two parliament's government and NGO on both sides Cooperation, bilateral and multi-lateral, combating international crime including terrorism, cyber security. Mongolia and India have been cooperating with each other in the area of cyber security domain. Mongolian Prime Minister expressed his appreciation to India's support to set up a cyber-security centre in Mongolia. Economic Cooperation closely cooperation with in the frame work of the UN, NAM, and other international organization with a view to furthering the cause of peace and international security, globally and in Asia, India and Mongolia support the evolution of open, balanced and inclusive security architecture in the Asia Pacific region based on collective efforts, considering legitimate interests of all states of the region guided by respect for norms and principles of international law. The two Prime Ministers reiterated their readiness to strengthen regional as well as multilateral cooperation, including through enhanced interaction in the UN and other regional and international organizations.

Some important visit of two countries India and Mongolia: The first ever and historic visit of Prime Minister Shri Narendra Modi to Mongolia (16-18 May 2015) as a part of 'Act East' policy, has proven to be a watershed period for India Mongolia relations. The declaration of 'Strategic Partnership', signing of 22-pointJoint Statement, announcement of USD 1 Billion LoC for development of Infrastructure in Mongolia - now being utilized for building 1st Oil Refinery - and 13 agreements prime minister Shri Narendra Modi visit Mongolia in May 2015 to mark the $60^{\text {th }}$ anniversary of establishment of diplomatic relation between India and Mongolia brought in a paradigm shift in our relationship the monument this generated has been sustained by several high level exchange in last four year two Prime Ministers 
underscored the significance of the visit in the backdrop of the 60th anniversary of diplomatic relations between Mongolia and India. It is the first ever visit by an Indian Prime Minister marking the dawn of a new era in Mongolia-India relations paved the way for elevation of our partnership to 'Strategic' level. 13 G2G agreements and 4 B2B agreements signed to expand our economic cooperation in various areas have come to manifest India's image as a strong 'third neighbour' has taken strong roots in the minds of Mongolian public and government structure. India's gifting of 150,000 doses of Covid Vaccine on Feb 22, 2021 was billed as a "historic" moment by Mongolian Deputy Prime Minister, as it was the Mongolia's first vaccine came from India.

They further noted with satisfaction the continued development of bilateral relations in the framework of a comprehensive partnership based on deep civilizational, historical, spiritual and cultural linkages, common democratic traditions and shared desire for regional as well as international peace and stability.

Given the shared desire to remain trusted partners, the two Prime Ministers pledged to further consolidate India-Mongolia comprehensive partnership, and agreed to elevate the level of the comprehensive partnership to a Strategic Partnership that is conducive to the common cause of the international community for peace and prosperity, and aligned with the collective interests of our two countries and our peoples.

\section{Political and Security Partnership}

The two Prime Ministers noted with satisfaction the increased high-level exchanges between the two countries in recent years and how these exchanges have significantly reinforced the momentum for cooperation between the two countries. Acknowledging the importance to maintain the frequency of reciprocal visits, both Prime Ministers noted that the nature and spread of international terrorism in recent years poses a threat to all humanity and requires global resolve and cooperative measures of the international community without double standards or selectivity. They agreed to direct concerned officials to work together for the adoption of the comprehensive convention on international terrorism. The Prime Ministers expressed hope that all safe havens and sanctuaries for terrorists will be wiped out without 
delay. Further, they also agreed to promote the exchanges of visits at all levels, namely between the government leaders, ministers, parliamentarians and senior officials and regular political dialogue on the side lines of multilateral events.

\section{Bilateral Defence and Security Cooperation}

The two Prime Ministers agreed to continue to work towards further intensifying bilateral defence and security cooperation through exchanges of high and mid-level visits, regular consultations and dialogue between the ministries of defence and other relevant organizations, including the national security councils, military personnel exchanges, capacity building, technical cooperation, special a Joint Working Group for Defence cooperation also convened annually. Mr. N. Enkhbold, Minister of Defence visited India in March 2018 and held bilateral talks with RRM, RM, NSA and COAS. The 8th JWG met in New Delhi (13-14 December 2016) and the Mongolian delegation was led by Deputy Defence Minister. The 9th JWG held from 6-8 May 2019 in Ulaanbaatar headed by JS (Air) and Mongolian Deputy Minister of Defence. zed vocational training, joint exercises in Special Forces and information security, collaboration in UN as well as to other international peacekeeping operations. Joint IndiaMongolia exercise 'Nomadic Elephant' is held annually. Last year it was held at Ulaanbaatar (Mongolia) from 10-22 September 2018 and in 2019 it was held from 05-18 October 2019 at Bakloh (HP), India. During 2020, it could not be held due to Covid enforced environment and is now expected to be held in the last quarter of 2021.Indian Armed Forces Observers regularly participate in the Annual multilateral peacekeeping exercise 'Khan Quest' in Mongolia. For 2021 exercises scheduled to be held in July.

\section{Commercial, Economic and Technical Cooperation}

The two Prime Ministers agreed to encourage development of equal and mutually beneficial trade, investment and economic cooperation, which is balanced, sustainable, and leads to prosperity in both countries. India and Mongolia signed MoU for establishment for joint trade, subcommittee and cooperation between the planning commission of India national development board of Mongolia were signed in 1994 to expand bilateral economic trade and agreement on trade and economic cooperation for MFN status to each other customs duties all 
other taxes on import and export, geology and mineral resources entered in September 1996. The mission regularly contributes consolidating and strengthening our trade and bilateral relation especially highlighted that Mongolia is beneficiary of India's single largest LoC for construction in December 2018, the embassy in coloration with Mongolia national chamber of commerce and industry organised commercial event, trade and investment opportunities in India to promote Indian pharmaceutical, agriculture, dairy, spice, tea, coffee, tourism and education sector in Mongolia.

Holding of two important Buddhist international conferences - Asian Buddhist Conference on Peace (ABCP) and Samvaad-III Buddhism-Hinduism Global Dialogue in Gandan Monastery in May and Sept 2019 respectively - in which India plays an important role, have contributed to consolidating of this shared heritage in recent years. As a part of 65th diplomatic anniversary celebrations, in April 2020, our Ministry of Culture have started reprinting of about 100 sets of '108 volumes of Mongolian Kanjur', which is expected to be completed in 2022. Incidentally, 25 volume set was virtually handed over by EAM to the then Chief Cabinet Secretary Mr Oyun Erdene (now Prime Minister) during the 7th Joint Commission Meeting. Subsequently, Prime Minister Shri Narendra Modi with Prime Minister J. Erdenebat met in the side lines of St. Petersburg International Economic Forum (June2017) and also met thrice with the current President Kh Battulga on the margins of Shanghai Cooperation Organization Summit at Qingdao, China (June 2018) and Eastern Economic Forum (EEF) in Vladivostok (Sep 2019) before holding full bilateral meeting in New Delhi during his State Visit to India (Sept 2019). PMs Meeting with Mongolian President was prominently noted in Mongolian media for enhancing bilateral relations.

Bilateral Cooperation Mechanism: India and Mongolia have 'India-Mongolia Joint Committee on Cooperation (IMJCC)' chaired at Ministerial level. 5th meeting of IMJCC was held in New Delhi in April, 2016 under the Chair of MoS for EA Gen (Retd.) V.K. Singh and Mr. L. Purevsuren, Foreign Minister of Mongolia. The 6th meeting of IMJCC was held in Ulaanbaatar on 25 April, 2018 co-chaired by Smt. Sushma Swaraj, External Affairs Minister and Mr. D. Tsogtbaatar, Foreign Minister of Mongolia. Owingto scheduling difficulties, the 7th IMJCC was not held in 2019 and finally took place virtually due to Covid enforced environment on Dec 3, 2020 and co-chairmanship of Dr. S. Jaishankar, External Affairs Minister and Mr. L. 
Oyun-Erdene, the then Chief Cabinet Secretary (Prime Minister since Jan 27, 2021).

\section{Foreign Office Consultations}

The last round of FOCs was held on 23 December 2016 in Ulaanbaatar. JS (EA) in MEA led the Indian side. The Acting Director, Department of Asia, Africa \& Pacific Regions co-chaired the consultations from the Mongolian side. Though the Mongolian State Secretary of MFA visited India in the first week of November 2018 \& held bilateral issues, it was not considered as FOC. The next round of FOCs is expected to be held in New Delhi at Secretary Level depending on mutually convenient dates. Co-operation in UN \& International Organizations: Mongolia has been traditionally supporting India and Indian candidates in the United Nations and various other international forums. It has supported us for the non-permanent seat of the UN Security Council (UNSC) for 2011-2012. India and Mongolia agreed to support to each other for UNSC non-permanent seats respectively for terms 2021-22 and2023-24. Mongolia voted in favour of India's proposal to Yoga's inscription into the list of UNESCO's Intangible Cultural Heritage. India also voted for registering Mongolian legacy on "Mongolian Traditional Custom to Worship Mountain and Ovoo" in the list of Intangible Cultural Heritage. Mongolia has publicly reiterated its support for India's membership to the permanent seat of expanded UNSC. Since 2017, Mongolian supported Indian candidature to:

- International Tribunal for the Law of the Sea (ITLOS)

- Executive Board of UNESCO for the term 2017-2021

- World Custom Organization (WCO)

- Council of the International Maritime Organization (IMO) in Category 'B' during the 30th session of the IMO Assembly in 2017,

- Advisory Committee membership election for Human Rights Council during the 36th meeting of HRC in Geneva in 2017

- International Court of Justice [For ICJ Mongolia's support was on reciprocal basis]

- Executive Board of the UNESCO at 39th General Conference for term 2017-2021

- 3rd group of International Civil Aviation Organization (ICAO) during the 40th Assembly, 2019 
- World Anti-Doping Agency (WADA) for the term 2020-2022

- Council of the International Maritime Organization (IMO) in Category 'B' during the 31st session of the IMO Assembly in 2019

- World Custom Organisation (xi) World Custom Organization (WCO)

- Asia Pacific Group seat of the UN Security Council for the term 2021-22

- Inter-governmental Committee for the Safeguard of Intangible Cultural Heritage

- UN Advisory Committee on Administrative and Budgetary (ACABQ) in November 2020

\section{Border Patrolling Cooperation}

The BSF (MHA) of India and the Mongolian General Authority for Border Protection (GABP) has been closely cooperating on border patrolling and related subjects for over eight years. Several proposals on capacity building\& technical assistance, including supply of integrated server to GABP by BSF are under consideration and likely to be completed by mid2021 provided COVID-19 situation in both countries is eased.

\section{Disaster Management Cooperation}

National Emergency Management Agency (NEMA) and National Disaster Management Agency (NDMA) picked up pace in the recent years. In 2018, 25 officers of NEMA were trained in India under ITEC. During the visit of President of Mongolia to India in September, 2019, a MoU on cooperation in the field of Disaster Management and Disaster Risk Reduction was signed between NEMA of Mongolia and NDMA of India and an 'Action Plan' for20212022 has also been negotiated between the two agencies in Feb 2021. However, some of the proposed activities in 2020-2021 could not be held due to Covid pandemic.

\section{Energy Cooperation}

A Working Group for cooperation in the field of nuclear energy has been set up between the respective agencies of the two countries i.e. the DAE and the Nuclear Energy Agency of Mongolia.

Mongolia like rest of the world was impacted badly during 2020 owing to Covid pandemic. 
However, using technological tools, the mission still organized 6-virtual 'Webinars' dedicated to Mining \& Mineral Cooperation, Healthcare and Pharma sector, Smart Cities, IT and related technologies, Dairy, Agriculture and Animal Husbandry sectors during Oct 2020 to Feb 2021 and another Virtual Meeting by Policy Times of India on 'Unleashing India's potential' was organized in Feb 2021 to bridge asymmetry of information and promote bilateral trade and commerce between India and Mongolia

Notwithstanding our excellent relations, the volume of bilateral trade is modest in value \& volumes. Main items of exports to Mongolia include medicines, mining, machinery and auto parts, etc. Imports from Mongolia include raw cashmere wool. However, India-Mongolia bilateral trade has registered significant growth during the last five years (2016-2020) as evident from the tables (Table $1 \&$ Table 2 ) given below:

Table 1: Bilateral Trade

Bilateral Trade Amount (in USD Million)

\begin{tabular}{|l|l|l|l|l|l|}
\hline Trade & $\mathbf{2 0 1 6}$ & $\mathbf{2 0 1 7}$ & $\mathbf{2 0 1 8}$ & $\mathbf{2 0 1 9}$ & $\mathbf{2 0 2 0}$ \\
\hline Export & 2.232 & 1.788 & 0.995 & 1.154 & 0.741 \\
\hline Import & 24.757 & 35.878 & 51.752 & 37.143 & 34.608 \\
\hline
\end{tabular}

(Sources: MNCCI)

Table 2: Participation of Mongolian companies in commercial events during 2020-21

\begin{tabular}{|l|l|l|l|}
\hline S. No. & Date \& Month & Name Of Event & Place \\
\hline 1. & 21 February 2020 & India Soft 2020 & Hyderabad \\
\hline 2. & $\begin{array}{l}24 \quad \text { December } \\
2020\end{array}$ & $\begin{array}{l}\text { Online webinar (Zoom application) - on } \\
\text { Agriculture }\end{array}$ & Mongolia \\
\hline 3. & 05 January 2021 & $\begin{array}{l}\text { Online webinar (Zoom application) - on Dairy } \\
\text { Product \& Animal Husbandry }\end{array}$ & Mongolia \\
\hline 4. & 07 January 2021 & $\begin{array}{l}\text { Online webinar (Zoom application) - on Smart } \\
\text { city and roll out of COVID Vaccine }\end{array}$ & Mongolia \\
\hline $\mathbf{5 .}$ & 21 January 2021 & $\begin{array}{l}\text { Online webinar (Zoom application) - on export } \\
\text { of coking coal to India }\end{array}$ & Mongolia \\
\hline 6. & 04 February 2021 & $\begin{array}{l}\text { Online webinar (Zoom application) - on Oil } \\
\text { Refinery Project }\end{array}$ & Mongolia \\
\hline
\end{tabular}




\begin{tabular}{|l|l|l|l|}
\hline 7. & 10 February 2021 & $\begin{array}{l}\text { Online webinar (Zoom application) - on Coal } \\
\text { organised by Coal Preparation Society of India }\end{array}$ & New Delhi \\
\hline
\end{tabular}

[Due to COVID-19 pandemic, Mongolian companies could not participate in commercial events physically from March 2020 to February, 2021]

(Sources: MNCCI)

\section{ITEC Assistance}

During Ex-President Elbegdorj's visit to India in 2009, 120slots per annum were offered to Mongolia under Indian Technical and Economic Cooperation (ITEC). From 2011-12, the number of these slots for civilian training programme were increased to 150 per year. e 201920, Ministry has approved 200 slots n 2020.Of the 200 allocated slots for FY 2020-21, only 2 slots were utilized for online training by NCCD, Mongolia Doctors in May, 2020 and the remaining slots have not been unutilized due to COVID-19 situation in both the countries.

\section{Humanitarian Assistance}

Worth USD 20,000 in the form of beds, bedrolls, toys, etc. for the children of herders in Sukhbaatar Aimag (severely affected by harsh winter 'Zud') was provided Mongolian experts on solar energy has been organized in India. Humanitarian assistance worth USD 50,000 was provided by the Government of India to the flood affected Provinces (Bayan Ulgii, Arhangai and Huvsgul) of Mongolia in August 2018.

\section{Medical Missions}

A team of 17 Indian Rotarians doctors led by Mr. R. K. Saboo, Ex-President of Rotary International undertook the second medical mission to Mongolia in May 2019 and conducted about 300 surgeries and donated medical equipment / medicines worth USD 12000. The first medical mission was undertaken by them in August 2017.

\section{Digital Connectivity Network}

The Government of Mongolia sought India's assistance on expansion of network in rural areas and improvement of infrastructure of main ICT network. Proposal is under consideration. 


\section{Cultural Cooperation}

The India-Mongolian Agreement on Cultural Cooperation was first signed in 1961 and a CEP between the two countries has always remained in force. The Agreement envisages cooperation in the fields of education by way of scholarships, exchange of experts, participation in conferences etc. The CEP was renewed in 2003, 2005, 2009and 2015 and most recently in Sept 2019 during the visit of Mongolian President until 2022. A "Festival of India" was organized in 2015 by the mission to mark the 60 years of diplomatic relations with Mongolia was organized in November 2015. A dance troupe from Mongolia performed in various cities in India in January 2018 and a traditional Indian Dance Troupe performed in 3 cities in Mongolia including capital city Ulaanbaatar in March 2018. A special Laddakh Mask Dance troupe visited Mongolia to perform at the Asian Buddhist Conference on Peace (ABCP) in June 2019 and also performed in Darkhan Province. There are regular exchanges of cultural troupe and performances of Indian performing groups that are well appreciated in Mongolia. In 2019, the mission has set up 5 special 'India-corners' at Rajeev Gandhi Polytechnic Institute.

\section{Atal Bihari Vajpayee Centre for Excellence in ICT}

An agreement was signed in September 2001 during the visit of Minister for IT Pramod Mahajan to Mongolia, the Atal Bihari Vajpayee Centre of Excellence (ABVCE) in Information and Communication Technology (ICT) in Mongolia and 5 Community Information Centres (CICs) in 5provinces (Khovsgol, Bulgan, Kharkhorin, Darkhan - Uuland Sukhbaatar). However, subsequently, at the request of Mongolian Ministry of Education (MMoE) it was decided that instead of 5 small centres, a full-fledged Centre of Excellence would be established using LoC of USD 20 million. PM Modi along with Mongolian PM laid the foundation stone of this centre of this Centre within the campus of Mongolian University of Science and Technology (MUST) in May 2015.

\section{Solar Energy}

The first solar energy electrification project from India was executed by the Central Electronics Ltd. and formally inaugurated in April 2006 in Dadal Soum. Training of Mongolian expert on solar energy has been organized in India. Medical Missions: May 2019 and conducted about 300 surgeries and donated medical equipment / medicines worth USD 12000. The first medical 
mission was undertaken by them in August 2017 when Indian doctors conducted neurosurgery, microsurgery, anaesthesiology, audiology, plastic surgery, etc. a Medical equipment worth of USD 30,000/- (approximately) donated to various Mongolian hospitals. Indian Rotarian have offered to treat 10 Mongolian poor children free of cost for their heart surgeries. The offer was reportedly utilized by Mongolian children in 2018 through the India-Mongolia Health Cooperation Centre.

\section{Conclusion}

It may be said that the richness of relationship between India and Magnolia is a result of the long standing people to people contact, mutual understanding between the people of both countries through enhancing education and cultural cooperation and common demarcating tradition and shared desired for regional as well as international peace and stability. India and Magnolia comprehensive partnership and agree to elevate the level of the comprehensive partnership to the strategic partnership that is conducive common cause of the international community for peace and prosperity, aligned with collective interest of two countries and its people. India and Magnolia relationship in present era would be the common yet new objective of the respective foreign policies.

\section{References:}

Embassy of India, Ulanbatar, http://www.eoi.gov.in/ulaanbaatar/

Embassy of India, Ulaanbaatar website: http://www.eoi.gov.in/ulaanbaatar/

Embassy of India, Ulanbatar, http://www.eoi.gov.in/ulaanbaatar-Mongolia-Embassy-ofIndiaUlaanbaatar/209956815734086?ref=hl

TOI (May 17, 2015). Joint Statement for India-Mongolia Strategic Partnership, Retrieved from https://timesofindia.indiatimes.com/india/joint-statement-for-india-mongolia-strategicpartnership/articleshow/47315412.cms

Powell, E.(2006).Mongolia.Archaeology,59(1),16-23. http://www.jstor.org/stable/41781443

Sneath, D. (2011). Mapping and the Headless State: Rethinking National Populist Concepts of Mongolia. In Sabloff P. (Ed.), Mapping Mongolia: Situating Mongolia in the World from Geologic Time to the Present (pp. 34-59). University of Pennsylvania Press. http://www.jstor.org/stable/j.ctt3fhwrc.10

Frederic, Gare and Mattoo, Amitabh (Eds) (2001). India and ASEAN-The politics of India's look East Policy, Manohar Publishers, New Delhi. 
Nagarajan S. (1998). Buddhism in South East Asia, Report of the Centre for Studies on IndoChina and South Pacific, Tirupati.

Oidov, Nyamdavaa (2015). Ancient Cultural, Ethnic and Religious Ties between Mongolia and India, World Affairs: The Journal of International Issues, Vol. 19, No. 4 (WINTER (OCTOBER-DECEMBER) 2015, pp. 150-159.

Hall, Ian (2012). India's New Public Diplomacy: Soft Power and the Limits of Government Action, Asian Survey 52 (6s): 1089-1110. doi:10.1525/as.2012.52.6.1089.

Sharad, Soni K (2006). India's New Role in East Asia: Implications for Mongolia, Mongolian Journal of International Affairs No.13 2006 pp.32-41. DOI: 10.5564/mjia.v0i13.6. 